\title{
THE ALTERNATION PROCESS IN BINOCULAR RIVALRY
}

\author{
BY W. J. M. LEVELT \\ Institute for Perception RVO-TNO, Soesterberg, The Netherlands
}

\begin{abstract}
Alternation frequency in binocular rivalry and relative dominance of stimuli in the right and left eyes are described in terms of an alternation model. The model is based on the assumption that the mean duration of the dominance of the stimulus in one eye is independent of the strength of this stimulus; the duration is assumed to be dependent only upon the strength of the stimulus in the contralateral eye. A provisional definition of stimulus strength is given. Evidence for assumptions and model is presented by a review of experimental literature on dominance and alternation in binocular rivalry, and by a number of experiments. Normal binocular fusion is considered.
\end{abstract}

In a previous paper (Levelt, 1965a) the author described some experiments which explored binocular brightness impression as a function of the respective luminances of the two monocular fields, and of an extra contour in one of these fields. Two mechanisms of binocular interaction appeared from this study. First, binocular brightness was constant as long as a sum of weighted left and right test field luminances was constant: $w_{l} E_{l}+w_{r} E_{r}=C$ where $E_{l}$ and $E_{r}$ denote left and right test field luminances (energy) respectively. It was shown that the sum of the weighting coefficients $w_{l}+w_{r}$ was constant for all of the situations studied. Stated otherwise, if the weighting coefficient for the field in one eye is increased, the weighting coefficient for the corresponding field in the other eye is decreased in the same measure. This was called the law of complementary shares. Secondly, the weighting coefficient for an eye can be increased by placing a contour in the monocular test field of the eye. The contribution of the other test field is reduced correspondingly. It was shown that the extreme case could be approximated in which $w$ for one eye tends to zero, as is the case if the other eye is fixating at or near a contour. This was called the contour mechanism; introduction of a monocular contour increases the weighting coefficient for that eye. In classical rivalry situations, e.g. a binocular crossing of bars, these mechanisms are incompatible. A contour is presented to both eyes, therefore both weighting coefficients tend to increase according to the contour mechanism. However, according to the law of complementary shares this is not possible, because the sum of the weighting coefficients is constant. The apparent resolution of this perceptual conflict is that the law of complementary shares is saved by an alternating process. Each eye, in its turn, has a proportional contribution of unity. This process of alternation can be influenced by a number of stimulus variables which seem to be related to the contour mechanism. It is reasonable to expect that stimulus conditions determining dominance of a monocular field in binocular brightness averaging also determine dominance in the alternation process.

The literature on alternation in binocular rivalry shows two major shortcomings. First, although the effect of a number of variables on the alternation process has been studied, there has been little attempt to propose underlying mechanisms that might explain how different variables can produce very similar effects. For instance, blurring the monocular stimuli and decreasing their luminance have the same effect 
on alternation; the alternation rate is reduced. Are they instances of the same underlying process? A second shortcoming is the following. Since Breese $(1899,1909)$ two features of the process have generally been studied. The first is the alternation frequency. The second is the dominance aspect of the process, i.e. the part of the total viewing time in which the right and the left stimuli are visible. Nobody has ever proposed a model which unifies both aspects of the same alternation process.

In this paper suggestions are made to fill in these gaps. A concept of stimulus strength is introduced to unify the effective variables, and a model is used to describe the alternation process of binocular rivalry in both its frequency and dominance aspects. The combination of stimulus strength, as defined, and the model lead to a number of testable deductions.

\section{Stimulus strength}

It is assumed that the features of the alternation process are determined by a uni-dimensional variable, which will be called stimulus strength $(\lambda)$, and which will, where possible, be defined up to order relations. As noted, we found in our previous study that the weighting coefficient of a monocular area for the binocular brightness impression increased when the mean distance between fixation point and a monocular contour near that area decreased; i.e. the effect of a contour declines with distance, or, alternatively, the weight is a function of the amount of contour per area. This leads to the assumption that stimulus strength in binocular rivalry is a monotonic increasing function of the amount of contour per area. Furthermore, our previous data suggested that the 'radius of action' of a contour diminishes when its contrast is reduced. Hence we assume that stimulus strength is directly related to the effectiveness of a contour: 'contour strength'. The intensity of a stimulus is conventionally defined as the ratio of stimulus to threshold-value. The equivalent definition of contour strength is the ratio of contrast to the difference threshold.

Starting from such a concept of contour strength, a large number of stimulus variables can be conceived of as special cases of contour strength variation. There are, then, two obvious ways of increasing contour strength: first by increasing contrast, and secondly by reducing the contrast difference threshold. This threshold depends on a large number of conditions.

A few of them are pertinent. Threshold contrast decreases with increasing luminance of the test object up to some value (about 20 trol.), but for high luminances a slight increase is often found probably due to saturation effects. Thresholds rapidly increase with the degree of eccentricity of the stimulus. Difference thresholds are smaller for large sizes of test object. The difference threshold increases if blur is introduced in the contours (see, for example, Ogle, 1961). And when the contrast is a combined colour and luminance contrast, our measure for contour strength is equivalent to the distance of the two colours in the colour space. This distance depends, in a complex way, on the state of colour adaptation of the eye.

For all experiments found in the literature, the conditions are scalable along such a dimension of ordered stimulus strength. And although the alternation model, which will now be developed will only be checked up to order relations, the model lends itself equally well to the use of metric relations. 
The alternation model

The merits of the model to be developed are independent of the definition of stimulus strength. It comprises only the relation between dominance and frequency aspects of the alternation process. For instance, stimulus variation $\mathrm{A}$ appears to affect alternation frequency if applied to both monocular stimuli: the model then predicts particular changes in dominance and rate of the alternation process, if the same variation $A$ is applied to only one of the monocular stimuli.

A contour presented to one eye is absolutely dominant as long as the other eye is presented with a homogeneous field. There are no 'saturation effects' in this situation, in the sense that the contour fades at times in favour of the homogeneous field. Sometimes it looks as if the latter phenomenon does occur, but this is due to Troxler's effect, and is not a result of binocular interaction. It is, therefore, a case of 'spurious rivalry' (Levelt, 1965b). Variations in contrast or luminance do not alter the general fact that the perception from one eye continues without interruption as long as no rival contour is presented to the other eye. This fact may have important implications for a model of binocular alternation. Thus, it is plausible that the mean period during which one of the stimuli is visible during binocular rivalry should not be a function of the strength of the same stimulus, but only of the strength of the contralateral stimulus.

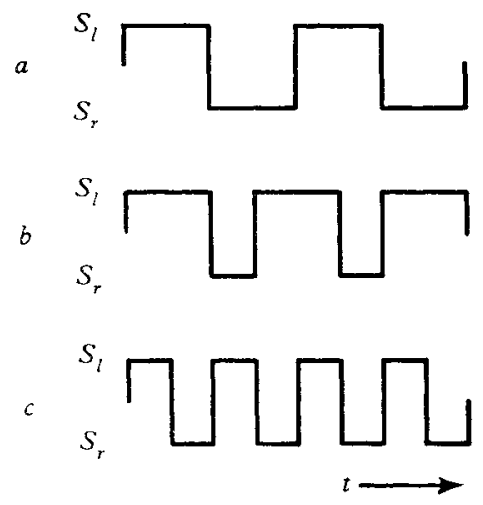

Fig. 1. The alternation model. Effects of variations in stimulus strength over time, $t:(a)$ $\lambda_{l}=\lambda_{r}$ giving $\bar{t}_{r}=\bar{t}_{l} ;(b)$ increase of $\lambda_{l}$ only leading to reduction of $\bar{t}_{r}$ and increase of frequency; (c) increase of both $\lambda_{l}$ and $\lambda_{r}$ leading to reduction of both $\bar{t}_{r}$ and $\bar{t}_{l}$ and increase of frequency.

The following symbols are used. $\vec{t}_{r}$ denotes the mean time during which the right stimulus is uninterruptedly perceived, and likewise $\bar{t}_{l}$ denotes the mean period length for the left stimulus. These symbols are used only in relation to the two-choice rivalry task, hence $\bar{t}_{r}+\bar{t}_{l}=\bar{T}$, the mean duration of the complete cycle. $S_{r}$ and $S_{l}$ are right and left stimuli respectively, and $\lambda_{r}$ and $\lambda_{l}$ are right and left stimulus strengths. The predominance of a stimulus is defined as the percentage of the total viewing time during which this stimulus is perceived. Hence, in symbols, $\bar{t}_{r}=f\left(\lambda_{l}\right)$ and $\bar{t}_{t}=f\left(\lambda_{r}\right)$, with $\bar{t}$ a monotonic decreasing function of $\lambda$. Before deducing some propositions, from this assumption, the idea may be stated still otherwise. If $S_{r}$ is perceived 
the conditional probability that during some time interval $t, S_{l}$ becomes visible, depends only on $\lambda_{l}$, not on $\lambda_{r}$, and inversely for a change from $S_{l}$ to $S_{r}$.

The precise characteristics of the distributions of $t$ or the function $f(\lambda)$ are discussed later. Even with $f(\lambda)$ unspecified it is possible to deduce four testable propositions on dominance and rate of alternation (cf. Fig. 1).

(I) Increase of the stimulus strength in one eye will increase the predominance of this stimulus. Deduction of the proposition for $S_{r}$ : the predominance of $S_{r}$ is $100 \bar{t}_{r} / \bar{T}=100 \bar{t}_{r} /\left(\bar{t}_{r}+\bar{t}_{l}\right)$ but $\bar{t}_{l}=f\left(\lambda_{r}\right)$, so an increase of $\lambda_{r}$ leads to a reduction of the denominator, and this means an increase of the predominance of $S_{r}$.

(II) Increase of the stimulus strength in one eye will not affect $\bar{t}$ for the same eye. This is a negative but important statement: $\vec{t}_{r}$ can only be affected by $\lambda_{l}$, not by $\lambda_{r}$.

(III) Increase of the stimulus strength in one eye will increase the alternation frequency. Increase of $\lambda_{r}$ reduces $\bar{t}_{l}$, and leaves $\bar{t}_{r}$ unaffected, hence $\bar{T}=\bar{t}_{r}+\bar{t}_{l}$ is reduced, and this is equivalent to an increase in rate of alternation.

(IV) Increase of the stimulus strength of both eyes will increase the alternation frequency. Increase of $\lambda_{l}$ and $\lambda_{r}$ leads to reduction of both $\bar{t}_{l}$ and $\bar{t}_{r}$, and hence of $\bar{T}$.

\section{REPoRted Data on aLternation Rate aNd DOMINaNCE}

Most of the reported work of binocular rivalry is concerned with alternation rate and dominance. A vast majority of the experiments are of the dominance type: the stimulus conditions are varied for one eye, and the effect on the predominance of that stimulus is measured. A smaller part of the literature is concerned with simultaneous changes of the conditions in both eyes: these studies normally give data on alternation rate. A minority of the studies give data on rate of alternation for the situation in which the stimulus presented to one eye is varied. A somewhat different classification is used below, because the model relates both rate and dominance aspects of the alternation process; the number of the proposition (I to IV), relevant to the experiment in question is added in brackets.

\section{Contrast experiments}

In most experiments contour strength has been varied, sometimes by varying contrast, sometimes by varying the difference threshold. Roelofs \& Zeeman (1919) were the first to stress the importance of contrast in binocular rivalry. Using orthogonal grids as stimuli, they showed that the dominance of an eye was reduced, if the contrasts in its grid were reduced, but irrespective of the absolute luminance level of this grid (I). Gellhorn and his collaborators found the same for coloured stimuli (I) (Gellhorn, 1924; Gellhorn \& Kuckenberg, 1924; Gellhorn \& Schöppe, 1924, 1925a,b). Mull, Armstrong \& Telfer (1956) used stimuli similar to Gellhorn's-a red and blue square on a neutral background presented to corresponding areas of the two eyes. They varied the contrast of the stimuli by using a grey or a black background. This did not notably affect the alternation rate: however, it is not possible to reconstruct what change in contrast took place by changing the background; probably only the contrast reversed, but the sign of the contrast is irrelevant for coloured stimuli, as Gellhorn showed (III). Alexander (1951) and Alexander \& Bricker (1952) found an increase of alternation rate if the contrast of the stimuli (grid patterns) 
was increased in both eyes (IV). Kakizaki (1960), using similar orthogonal grids as stimuli, found an increase of predominance with contrast for one eye (I); the rate of alternation increased with increasing contrast of the pattern (III). Bright bars on a black background were used as stimuli by Kaplan \& Metlay (1964). Increasing the luminance of the bar in one eye led to dominance approaching $100 \%$ (I), nevertheless alternation occurred even when the two fields were very different in brightness. These authors also noticed an increase in rate of alternation (III), and an increase in rate with increased illumination of both bars (IV), but increased luminance above $4 \log$ trol. slightly decreased the rate. This accords fairly well with the saturation hypothesis for a decrease in difference threshold at high luminances.

Amount of contour per area. Allers (1935) found an increase of predominancy of an eye, if the amount of contour per area for that eye was increased (a pattern of straight bars was replaced by a pattern of waved bars) (I). Similarly, Alexander (1951) found a decrease of rate, if gaps were introduced in the bars of the two orthogonal grids that he used (IV). A similar example is to be found in Gellhorn's work (op. cit.). Studying the effect of colour adaptation in rivalry, he presented two differently coloured squares on corresponding points of the two eyes. He now introduced an additional stimulus of some other colour near the square in one eye, and found an increase of dominance for that square. To his surprise this appeared to be independent of the colour of the additional stimulus. In our opinion the matter is simply one of introducing extra contours (I). A direct test of the radius of action of a contour has only been made by Kaufman (1963). He presented a horizontal bar to the left eye, and two vertical bars to the right eye, so that the binocular impression was an intersection of a horizontal and two vertical lines. The observer passed a key whenever the part of the horizontal bar between the vertical bars disappeared. The amount of suppression appeared to be a function of the angular separation $\theta$ of the two vertical bars (I). Complete suppression of the segment hardly occurred beyond $\theta=2^{\circ}$. The suppression stabilized at about $50 \%$, for angular separations within $14 \mathrm{~min}$ of arc. Kaufman also found an increase in rate with a decrease of $\theta$ (III).

Luminance. There is not much unanimity on the role of luminance per se in rivalry. The results of experiments in which a constant (and finite) contrast was used at different luminance levels are rather divergent. This is not surprising, because the difference threshold is a curvilinear function of luminance. For low luminance levels a small luminance change corresponds to a large change in threshold, and hence to a large change in contour strength. For higher luminances the threshold is practically constant, and at some level a slight increase in threshold is often measured. The divergence of the results may be due to the differences in chosen luminance levels. Breese $(1899,1909)$ found an increase of alternation frequency by increasing the luminance of the two grid patterns used (IV), and a shift in dominance if the luminance was increased for one eye only (I). Roelofs \& Zeeman (1919) did not find effects of luminance level variations, whereas Mull et al. (1956) did find such effects on alternation rate (IV). But none of these authors give absolute values for the luminances used, and one of our experiments was therefore concerned with this point.

Eccentricity of the test target changes the difference threshold. It was again Breese (1909) who presented the first data on this variable. He found that alternation rate 
decreased towards the periphery of vision (IV); the same tendency appeared in a study of Wilde (1938) who used two crossing bars as stimuli (IV). The other results of Wilde's rivalry experiments appear not to be due to binocular interaction but to spontaneous fading of an image in the periphery of vision (Troxler's effect cf. Levelt $1965 b)$.

Variations in size of the test target were only studied by Breese (1909). For larger grids, the rate was increased (IV). The main effect was in the region of small sizes, but, unfortunately, visual angles were not given.

Adaptation variables have been studied by Gellhorn (op. cit.). For his coloured stimuli, he found a decrease of dominance in rivalry for a stimulus, if the eye was preadapted to the colour of that stimulus. The colour contrast is reduced in this way (I).

Blur effects were again initially studied by Breese (1909). In one of his experiments he blurred the contours of the grids in both eyes by out-of-focus projection. In this way not only is blurring of contours introduced, but also reduction of contrast. Hence it is not certain whether the reduction of alternation rate that he found (IV) should be mainly attributed to the effect of blur on the difference threshold; one of our experiments was therefore on blur and rivalry, with contrast kept constant.

The aim of this excursion into the literature was to look for confirmation of the proposed alternation model and for counter-evidence. The booty of the expedition can now be summarized.

1. Proposition I has often been the objective of experimentation and has generally been confirmed, but a simple check of this proposition has more to say about the usefulness of the concept of stimulus strength than about the internal consistency of the model. A check on consistency is only possible if the effects of same stimulus variable are also tested in relation to the other propositions. Examples were given in the work of Breese, who found the predominance-effect (I) and the rate-effect (IV) when monocular and binocular increases in stimulus luminance were introduced. The same effect was found by Kaplan \& Metlay (1964); moreover these authors found rate to increase when the luminance of only one stimulus was increased (III). Kakizaki (1960) found effects I and III for uniocular increase of contrast, and finally Kaufman's (1963) data show these two effects for the variable contour-per-area. These studies confirm the internal consistency of the model as far as propositions I, III and IV are concerned. But no data at all have been found which bear on proposition II, the most specific of the propositions. On the contrary, the general opinion seems to have been that the mean duration of a dominance period is increased by strengthening the stimulus.

2. There are three components in our tentative definition of stimulus strength: stimulus strength increases (i) with increasing contrast, (ii) with decreasing difference threshold, and (iii) with diminishing angular distance between stimulus contour and target in the other eye. Striking counter-arguments against the use of this parameter were not found, but this is little testimony to its adequacy. More data are needed. The three components have therefore been studied for one type of stimulus: first in relation to distance, then to the effects of contrast and of threshold variations. The last two experiments were also designed to study proposition II in relation to propositions I and III. 
The only point of clear controversy appears to be the effect of the absolute luminance level of the stimuli. From our definition of contour strength no luminance effect is expected as long as contrast and difference threshold are constant, for luminances beyond about 20 trol. This point was also subjected to experiment.

\section{Experiments ON THE ALTERNATION MODEL}

\section{Experiment I. Radius of action}

The problem. In studies in which the amount of contour per area is varied, the basic question concerns the 'radius of action' of a contour. The present problem is: how large can the angular separation between a left and a right eye contour be in order still to provide moments of complete suppression of one of them in binocular vision? Kaufman's (1963) data concern foveal vision, no data have been found on peripheral vision.
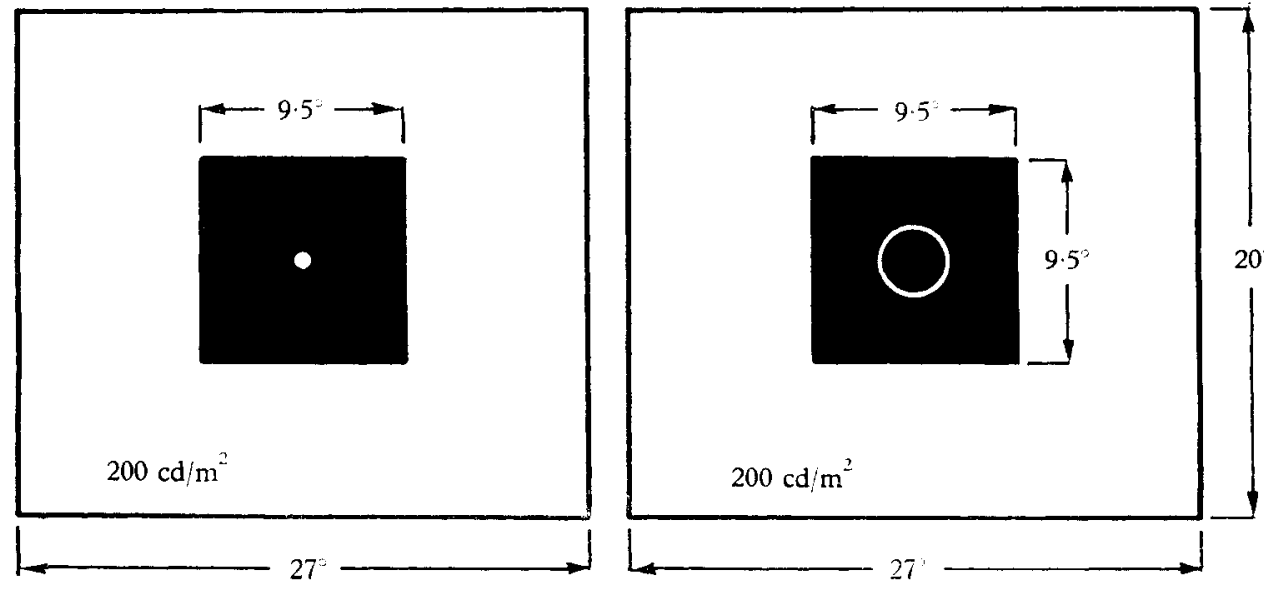

Fig. 2. Stimuli used in Expt I. The point stimulus on the left had a diameter of $20^{\prime}$ (luminance: $200 \mathrm{~cd} / \mathrm{m}^{2}$ ). The circle on the right had a variable diameter and a width of $6^{\prime}$ (luminance: $\left.200 \mathrm{~cd} / \mathrm{m}^{2}\right)$.

Apparatus and stimuli

\section{Method}

The apparatus has been described in detail elsewhere (Levelt, 1965a). The observer looks into a kind of stereoscope through $1 \mathrm{~mm}$ artificial pupils. The luminances of the left and right monocular fields can be controlled. The stimuli used in the present experiment are given in Fig. 2. The black squares were fused binocularly. In this way the white (left) test point is prevented from drifting within the white (right) circle. The ring and the test point had a constant luminance of $200 \mathrm{~cd} / \mathrm{m}^{2}$. We used a ring as 'suppressing' stimulus in order to have a constant distance in all directions between left and right contours.

\section{Procedure}

The total disappearance time of the left test spot during a 1 min period of observation was measured as a function of the inner diameter of the surrounding circle. The diameter was varied in $0.5^{\circ}$ steps from $4^{\circ}$ to $1^{\circ}$. Furthermore, the condition of 'no circle' was tested, for comparison with Troxler's effect. Both central fixation, i.e. fixation of the test spot, and peripheral fixation were tested: in the latter case an extra fixation point was introduced for both eyes, $3^{\circ}$ above the test spot. Measurements started with the Troxler condition, followed by a descending series of circle diameters. Two subjects took part in this experiment. 


\section{Results}

The results are shown in Fig. 3. The radius of action is much larger for peripheral than for foveal vision. For a $3.5^{\circ}$ circle, it is distinctly above the Troxler level in peripheral vision, whereas in foveal vision complete suppression only occurs for $1^{\circ}$ and $1.5^{\circ}$ circles. For all other diameters complete suppression does not occur (although nearly complete suppressions often occur). If we take experimental differences into account, our results for foveal vision are in fair agreement with Kaufman's, as to the maximum extent of complete suppression. In terms of our model, proposition I is confirmed with peripherality and radius of action as components of stimulus strength.
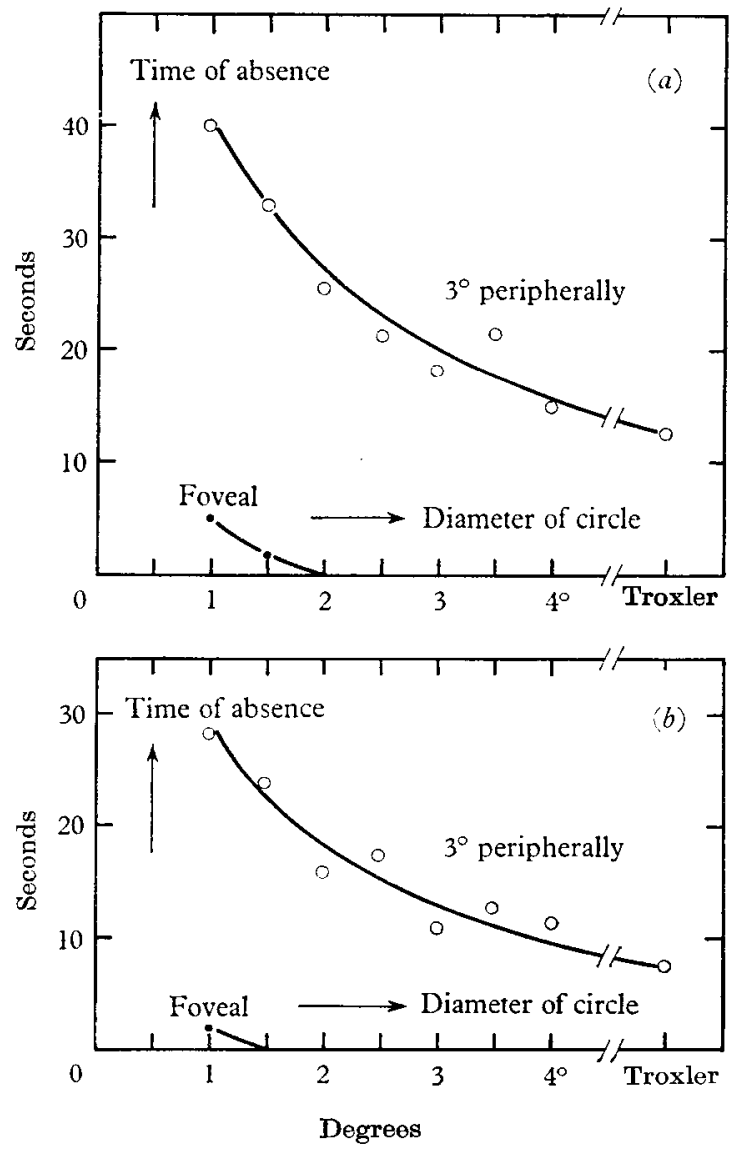

Fig. 3. Suppression of left test-spot as a function of the diameter of the right circle for central and peripheral vision for two observers $(a)$ W.L. (b) A.v.d.B.

\section{Experiment II. Blur}

This experiment and Expt. III were designed to test the relation between propositions I, II, and III of the alternation model.

The problem. Blurring the stimulus in the left field should reduce its contour 
LEVELT, W. J. M., The alternation process in binocular rivalry, British Journal of Psychology,

strength, resulting in a reduction of the predominance of the left stimulus (I), and reduction of the alternation rate (III). However, the mean dominance time $\bar{t}_{l}$ of this stimulus should not be affected (II).

\section{Stimuli}

\section{Method}

The stimuli are shown in Fig. 4. The blur-condition B was produced by placing an extra lens in the left light pathway of the apparatus. The result was the luminance distribution shown in Fig. 5. The luminance distribution under the non-blurred condition $\mathrm{A}$ is also shown for comparison.
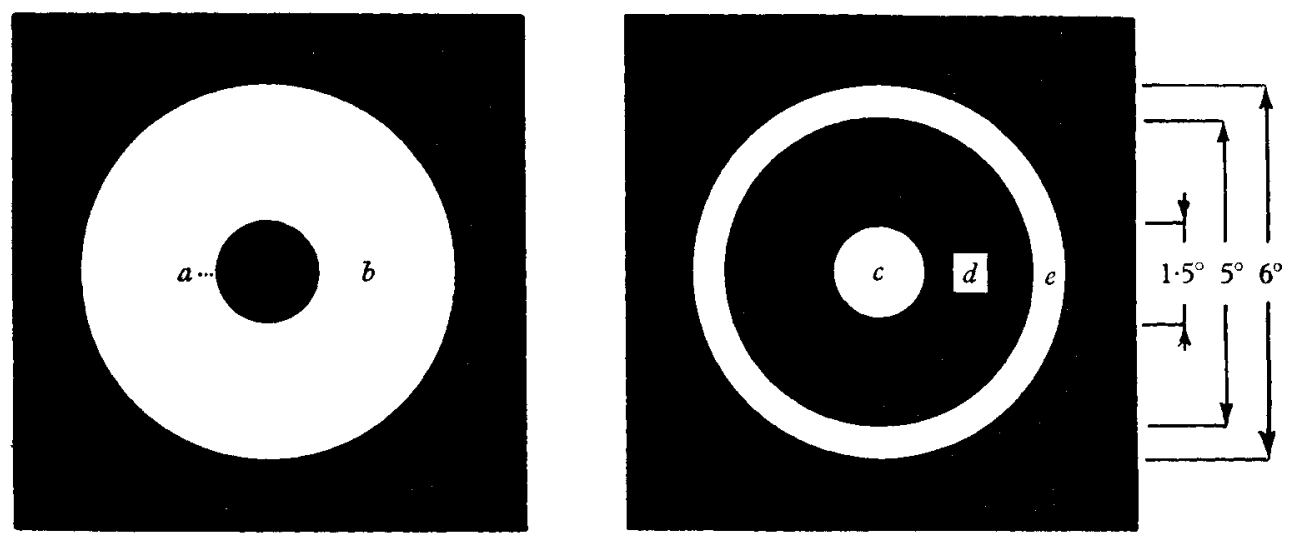

Fig. 4. Stimuli of Expts II and III. The Iuminances in Expt II were: for Expt II: $a=40$ $\mathrm{cd} / \mathrm{m}^{2}, b=400 \mathrm{~cd} / \mathrm{m}^{2}, d=23 \mathrm{~cd} / \mathrm{m}^{2}, c$ and $e=400 \mathrm{~cd} / \mathrm{m}^{2}$; and in Expt III : condition A : $a=85 \mathrm{~cd} / \mathrm{m}^{2}, \quad b=710 \mathrm{~cd} / \mathrm{m}^{2} ;$ condition B: $a=85 \mathrm{~cd} / \mathrm{m}^{2}, \quad b=100 \mathrm{~cd} / \mathrm{m}^{2} ;$ condition $\mathrm{C}$ : $a=12 \mathrm{~cd} / \mathrm{m}^{2}, b=100 \mathrm{~cd} / \mathrm{m}^{2} ;$ all conditions : $c=100 \mathrm{~cd} / \mathrm{m}^{2}, d=5.75 \mathrm{~cd} / \mathrm{m}^{2}$, and $e=100$ $\mathrm{cd} / \mathrm{m}^{2}$.
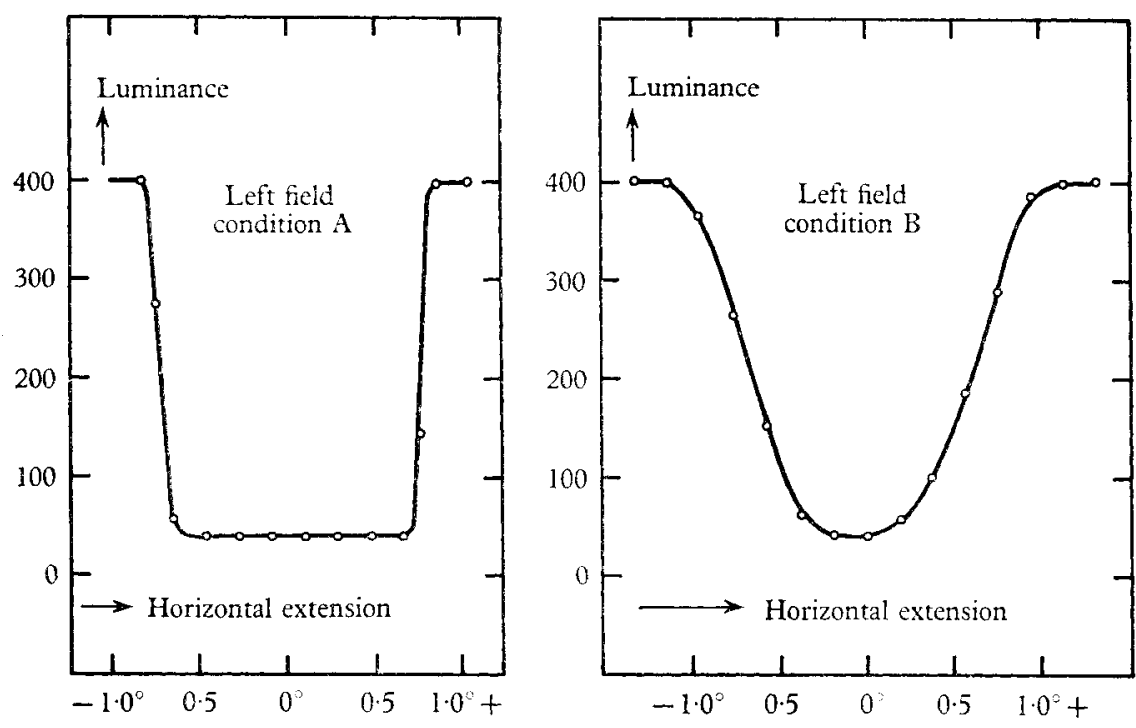

Fig. 5. Luminance density of the dark spot in the left field of Fig. 4 for the non-blur and the blur conditions, Expt II. 
Moreover, the total amount of light from an area somewhat larger than $a$ (in Fig. 4, but including it, was measured by means of a photomultiplier. No difference was found between conditions $\mathbf{A}$ and $B$. Hence, under the present conditions, the introduction of blur did not affect contrast or total amount of light of the left stimulus.

Procedure

The subject looked through artificial pupils, diameter $1 \mathrm{~mm}$, and fixated the centre of $a$ and $c$ in Fig. 4. He kept the key depressed for as long as the left stimulus was dominant. Ten subjects took part in the experiment. They observed each condition twice in random order. Each inspection period lasted 1 min.

\section{Results}

Two analyses of variance were applied to the results, one to the dominance scores, and another to the frequency scores. Of the dominance scores, the mean predominance for the ten subjects in the unblurred conditions was $50.9 \%$ (or $30.55 \mathrm{sec} / \mathrm{min}$ ). For the blurred condition, it was $26.5 \%(15.87 \mathrm{sec})$. The difference is significant $(P<0.001)$ and confirms proposition I. The mean frequency scores for the A and B conditions were $12 \cdot 20$ and $6 \cdot 40 / \mathrm{min}$ respectively. This difference was significant $(P<0.005)$ and confirms proposition III.

As to the proposition II, the mean $\bar{t}_{l}$ was $2.50 \mathrm{sec}$ in the A condition, and $2.48 \mathrm{sec}$ in the $\mathrm{B}$ condition (s.E. $=0.5$ ). No analysis of variance is necessary to appreciate that $\bar{t}_{l}$ evidently was not affected with the stimulus strength in the right field constant.

\section{Experiment III. Contrast}

The problem. This last experiment serves a number of purposes. First, the effect of contrast variation and luminance variation on rivalry were to be compared. The prediction was that, for a sufficient level of luminance, luminance variation would have a negligible effect on rivalry, but that there would be a large effect of variation in contrast. Secondly, separate analyses of predominance and frequency aspects of the alternation would give information about propositions I and III. And finally, calculation of $\bar{t}_{l}$ would provide another test of proposition II.

Stimuli

\section{Method}

Except for their luminances, the stimuli were the same as in Expt II. The luminance values are given in the legend to Fig. 4. Three conditions were used. In conditions $A$ and $C$, the contrast of the left test spot was $7 \cdot 35$, but the stimuli differ in the level of total luminance. The luminance of the left field under condition A was 7.1 times larger than its luminance in C. In condition B, the contrast was set at $0 \cdot 18$, much less than under the other two conditions. On the other hand, the luminance level of the stimulus lay between the levels of the $A$ and $C$ stimuli. In fact the test spot had the same luminance as under condition $A$. and the surrounding field had the same luminance as under condition C. In this luminance region the difference threshold is fairly constant. The right field was the same for all conditions.

\section{Procedure}

Ten subjects were presented with the three conditions in random order, with one repetition of the whole cycle, giving six 1 min observation periods per subject. The subject was instructed to push the key for as long as the black on white test spot was visible. 
Results

Two analyses of variance were carried out, one on the predominance scores and one on the frequency scores. The average predominance of the left field for condition A was $41.9 \%(25.13 \mathrm{sec})$, for $\mathrm{B} 27.6 \%(16.55 \mathrm{sec})$, and for C $46.6 \%(27.93 \mathrm{sec})$. Scheffé's method was used to compare these means. It revealed that the differences between $\mathrm{B}$ and $\mathrm{A}$ and between $\mathrm{B}$ and $\mathrm{C}$ were significant $(P<0 \cdot 001)$. The small

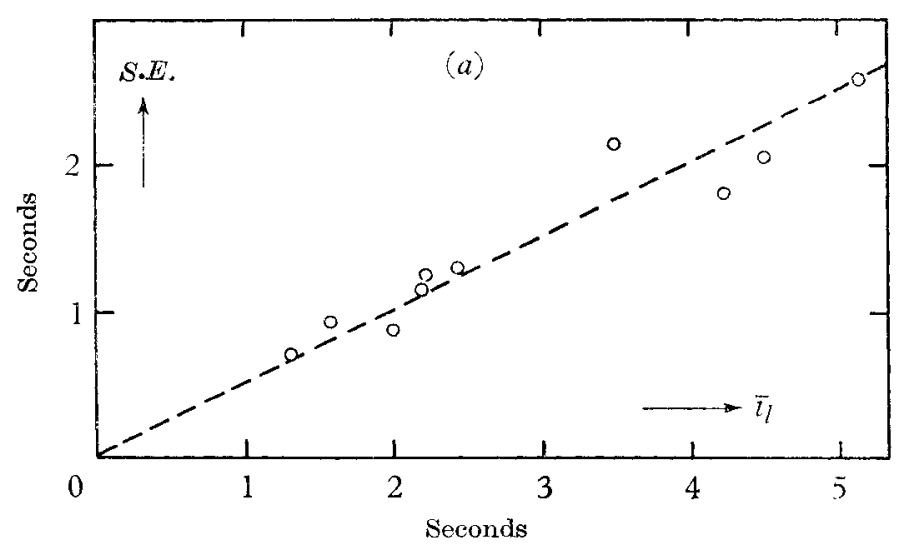

Fig. 6. Relation of mean and s.e. in the blur experiment.

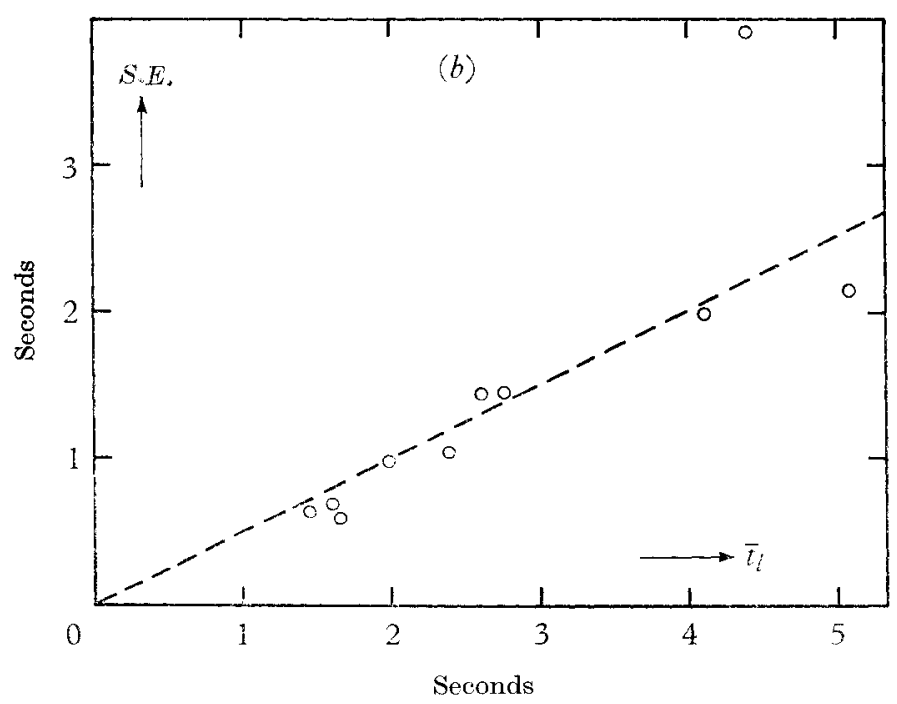

Fig. 7. Relation of mean and S.E. in the contrast experiment.

difference between $\mathrm{A}$ and $\mathrm{C}$ was not significant. These results corroborate the findings of Roelofs \& Zeeman (1919) that luminance level is immaterial to dominance in binocular rivalry, as long as contrast is preserved. The effect of changes in contrast appears to be important in that the low contrast in B resulted in low predominance for the left field (I). 
The analysis of frequency scores again showed significant differences between conditions $(P<0 \cdot 001)$. Mean frequency under condition $\mathrm{A}$ was $9 \cdot 6$, under $\mathrm{B} 6 \cdot 4$, and under $\mathrm{C} 10 \cdot 9 / \mathrm{min}$. Again, only the differences between $\mathrm{B}$ and $\mathrm{A}$ and between $\mathrm{B}$ and $\mathrm{C}$ were significant $(P<0.001)$, in agreement with proposition III.

As to proposition II, for $\mathrm{A}, \mathrm{B}$, and $\mathrm{C}, \bar{t}_{l}$ was $2 \cdot 62,2 \cdot 59$, and $2.56 \mathrm{sec}$, respectively, which again confirms the proposition.

\section{Conclusions}

The concept of stimulus strength seems to have merit at least up to order relations. But even at this level there are still gaps in our knowledge. For example, what are the relations between levels of contrast on the one hand and levels of blur on the other hand? Nevertheless, a number of specific predictions could be made, as for instance about the effects of contrast and luminance variation. 'There is much evidence for an alternation model based on the assumption that the mean duration of the predominance period of one eye is a function only of the stimulus strength in the other eye. Proposition II is supported by Expts II and III. This assumption moreover generated hypotheses about both dominance and rate in the alternation process, none of which had to be rejected.

\section{Fusion and alternation}

At the beginning of this paper it was shown that the law of complementary shares conflicts with the contour mechanism if non-corresponding contours are presented to the eyes, but there is no a priori reason to expect no conflict if the eyes are presented with corresponding contours, i.e. in normal binocular vision. In the latter case one cannot be aware of an alternation process, because of the law of complementary shares. The impression is exactly the same for all values of $w_{l}$ and $w_{r}$, as long as their sum remains constant.

Authors on binocular rivalry customarily extend the rivalry process to cover the situation of fused images. An early author to do so was Du Tour (1760), and for more than two centuries this point of view has been raised repeatedly. In this century Verhoeff (1935) has assumed that only one of the retinal images is present to consciousness at a time; similar suggestions have been made by Asher (1953) and recently by Hochberg (1964). Panum's fusional area can be understood in this way. Ogle's (1950) measurements on the horizontal extent of Panum's area give values of 6-8' in the foveal field, that is of the region within which one line is always seen when a pair is presented. These values compare with Kaufman's (1963) data on extent of inhibition: he found a constant value of about $50 \%$ inhibition of the horizontal line segment for $\theta<14^{\prime}$ (separation of vertical lines in the contralateral eye). Hence, the extent of complete suppression of a horizontal line in rivalry is also about $7^{\prime}$.

The experiments by Hubel \& Wiesel $(1959,1962)$ have shown that for most cells in the visual cortex of the cat a functional predominance of one of the eyes could be measured. However, absolute dominance appeared to be exceptional. In our earlier experiments (1965 a) absolute predominance of one eye in binocular brightness averaging also appeared to be exceptional. The proportional contribution of an eye ranged between 0 and 1 , but was mostly somewhere in between. Recent experiments by Lansing (1964) showed that the EEG response to a fluctuating left eye stimulus was 
reduced during periods of perceptual dominance of the right eye stimulus. But this was also no all-or-none effect; different degrees of EEG reduction were measured. It may equally be the case that alternation in binocular vision is not an all-or-none effect, as has been generally assumed. It is suggested that the contributions of the eyes are continuously balanced in the range between 0 and 1 , while obeying the law of complementary shares, and that the mean position of the balance is determined by eye dominance and stimulus factors, as discussed in this paper.

\section{REFERENCES}

Alexander, L. T. (1951). The influence of figure-ground relationships in binocular rivalry. J. exp. Psychol. 41, 376-81.

Alexander, L. T. \& Bricker, P. D. (1952). Figure ground-contrast and binocular rivalry. J. exp. Psychol. 44, 452-4.

Allers, R. (1935). Über einige Unterschiede zwischen dem ein- und dem beidäugigen Sehen und über den Einfluss seelischer Momente auf einfache Leistungen des Gesichtssinnes. S.B. Akad. Wiss., Wien, 144 (math.-naturwiss. Kl.), 33-79.

Asher, H. (1953). Suppression theory of binocular vision. Brit. J. Ophthal. 37, 37-49.

Breese, B. B. (1899). On inhibition. Psychol. Monogr. 3, whole no. 11.

Brefese, B. B. (1909). Binocular rivalry. Psychol. Rev. 16, 410-5.

Du Tour, E. F. (1760). Discussion d'une question d'optique. Mém. math. phys. Acad. Roy. Sci. Paris, 3, 514-30.

Gellhorn, E. (1924). Quantitative Untersuchungen über den Wettstreit der Sehfelder. III. Zur Kenntnis der psychologischen Ursachen des Wettstreites. Pflüg. Arch. ges. Physiol. 206, $237-49$.

Gellionn, E. \& Kuokenbera, J. (1924). Quantitative Untersuchungen über den Wettstreit der Sehfelder. I. Der Einfluss der Helligkeit der Farben auf den Wettstreit mit besonderer Berücksichtigung der Kontrastwirkungen. Pfiüg. Arch. ges. Physiol. 206, 194-210.

GellHoRn, E. \& SchöPPE, C. (1924). Quantitative Untersuchungen über den Wettstreit der Sehfelder. IT. Die Änderung des Wettstreites durch Umstimmung des Sehorgans. Pflüg. Arch. ges. Physiol. 206, 211-36.

Gellhorn, E. \& SchöpPe, C. (1925a). Quantitative Untersuchungen über den Wettstreit der Sehfelder. IV. U̇ber den Einfluss von farbigen Nebenreizen auf den Wettstreit. Pflüg. Arch. ges. Physiol. 208, 393-407.

Getlhorn, E. \& Schöppe, C. (1925b). Quantitative Untersuchungen über den Wettstreit der Sehfelder. V. Über den Einfluss der Beleuchtungsstärke sowie der Adaptation auf die Grösse der Wettstreitquotienten. Pflüg. Arch. ges. Physiol. 208, 408-17.

Hochberg, J. (1964). A theory of the binocular cyclopean field: On the possibility of simulated stereopsis. Percept. mot. Skills 19, 685 .

Hubel, D. H. \& Wiesel, T. N. (1959). Receptive fields of single neurones in the cat's striate cortex. J. Physiol. 148, 574-91.

Huber, D. H. \& WIEsel, T. N. (1962). Receptive fields, binocular interaction and functional architecture in the cat's visual cortex. J. Physiol. 160, 106-54

KaKIZAKI, S. (1960). Binocular rivalry and stimulus intensity. Jap. psychol. Res. 2, 94-105.

KaPlan, I. T. \& Metlay, W. (1964). Light intensity and binocular rivalry. J. exp. Psychol. 67, $22-6$.

KaUFMaN, L. (1963). On the spread of suppression and binocular rivalry. Vision Res. 3, 401-15.

LANSING, R. W. (1964). Electroencephalographic correlates of binocular rivalry in man. Science 146, 1325-7.

LeVELt, W. J. M. (1965a). Binocular brightness averaging and contour information. Brit. $J$. Psychol. 56, 1-13.

Levelt, W. J. M. (1965b). On Binocular Rivalry. Soesterberg: Rep. Institute for Perception RVO-TNO; unpublished doctoral thesis, University of Utrecht.

Muld, H. K., Armstrong, \&. G Telfer, B. (1956). The effect of brightness upon reversible perspectives and retinal rivalry. Amer. J. Psychol. 69, 123-5. 
LEVELT, W. J. M., The alternation process in binocular rivalry, British Journal of Psychology, 57:3/4 (1966:Nov.) p.225

OGLE, K. N. (1950). Researches in Binocular Vision. Philadelphia and London: Saunders.

OGLE, K. N. (1961). Foveal contrast thresholds with blurring of the retinal image and increasing size of test stimulus. J. opt. Soc. Amer. 51, 862-9.

Rowlofs, C. O. \& Zieman, W. P. C. (1919). Über den Wettstreit der Konturen. v. Graefes Arch. Ophthal. 99, 79-104.

VerhoefF, F. H. (1935). New theory of binocular vision. A.M.A. Arch. Ophthal., 12, 151-75.

WILDE, K. (1938). Figur und Fläche im Wettstreit. Psychol. Forsch. 22, 26-58.

(Manuscript received 19 March 1965) 